Supplement of Biogeosciences Discuss., 11, 17579-17629, 2014

http://www.biogeosciences-discuss.net/11/17579/2014/

doi:10.5194/bgd-11-17579-2014-supplement

(C) Author(s) 2014. CC Attribution 3.0 License.

(c) (1)

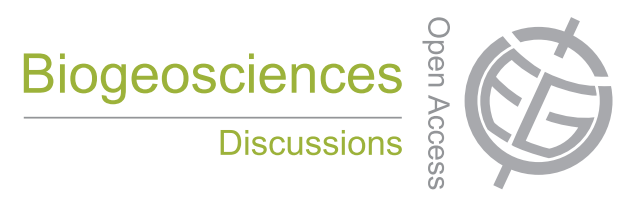

Supplement of

\title{
Daily burned area and carbon emissions from boreal fires in Alaska
}

S. Veraverbeke et al.

Correspondence to: S. Veraverbeke (sander.veraverbeke@uci.edu) 
Supplementary Table 1. Land cover aggregation scheme applied on Fuel Characteristic Classification System (FCCS) map (Ottmar et al., 2007). The numbers between brackets represent the FCCS codes.

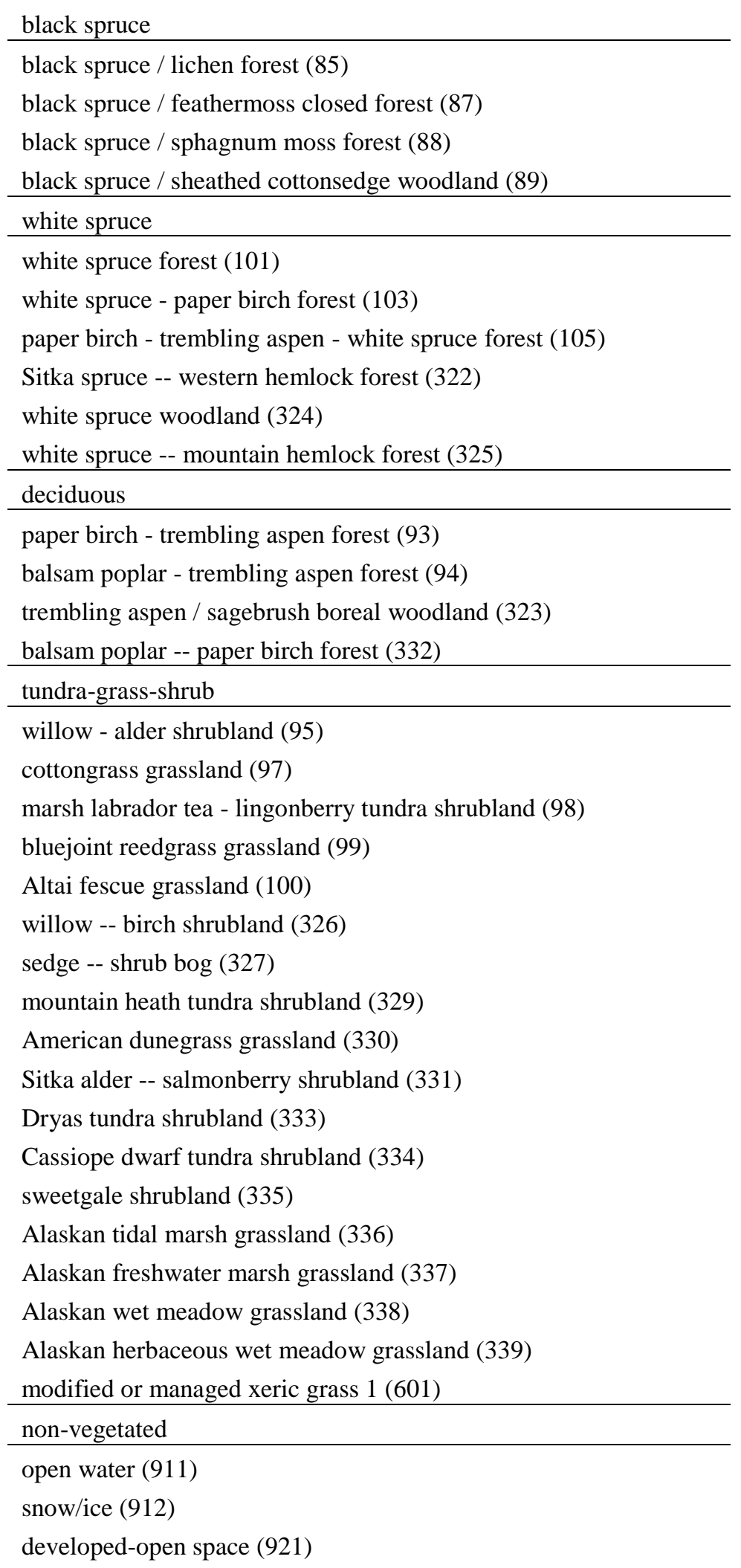


developed-medium intensity (923)

barren (931)

sparsely vegetated (933)

agriculture-cultivated crops and irrigated agriculture (982) 
Supplementary Table 2. Location, year, depth of burn and carbon consumption of the field plots used in this study. (B: Boby et al. (2010), R: Rogers et al. (2014), T: Turetsky et al. (2011)). Depth of burn measurements were available for all sites. Direct estimates of belowground carbon consumption were available for the B and R plots. Direct estimates of aboveground carbon consumption were available for the B and R plots, with exception of one of the B plots. For the $\mathrm{T}$ data, belowground consumption was calculated using the soil-carbon accumulation curves per topographic class provided in Turetsky et al. (2011) (Figure S2). We used a digital elevation model (section 2.3.3) resampled to $500 \mathrm{~m}$ resolution for assigning the topographic classes to the field plots. Concave flat (slope $\leq 2 \%$ ) areas were classified as lowland (L), convex flat areas were as upland (U). Sloped terrain was categorized as North (N) aspect (aspect $\geq 315^{\circ}$ or $<45^{\circ}$ ), South (S) aspect (aspect $\geq 135^{\circ}$ and $<225^{\circ}$ ), and East or West aspect (aspect $\geq 45^{\circ}$ and $<135^{\circ}$, or $\geq 225^{\circ}$ and $<315^{\circ}$ ).

\begin{tabular}{|c|c|c|c|c|c|c|}
\hline $\begin{array}{l}\text { latitude } \\
\left({ }^{\circ} \mathrm{N}\right)\end{array}$ & $\begin{array}{l}\text { longitude } \\
\left({ }^{\circ} \mathrm{W}\right)\end{array}$ & $\begin{array}{l}\text { fire } \\
\text { year }\end{array}$ & $\begin{array}{l}\text { depth of } \\
\text { burn }(\mathrm{cm})\end{array}$ & $\begin{array}{c}\text { belowground C } \\
\text { consumption }\left(\mathrm{kg} / \mathrm{m}^{2}\right)\end{array}$ & $\begin{array}{c}\text { aboveground } \mathrm{C} \\
\text { consumption }\left(\mathrm{kg} / \mathrm{m}^{2}\right)\end{array}$ & reference \\
\hline 66.31539 & 150.40571 & 2004 & 18.8 & 4.59 & I & B \\
\hline 66.20925 & 150.27001 & 2004 & 11.6 & 0.95 & 0 & B \\
\hline 66.21316 & 150.26391 & 2004 & 8 & 1.46 & 0.1 & B \\
\hline 66.16861 & 150.20422 & 2004 & 12.3 & 4.53 & 0.4 & B \\
\hline 66.16364 & 150.20207 & 2004 & 14.8 & 4.68 & 0.43 & B \\
\hline 66.15127 & 150.18096 & 2004 & 14 & 4.58 & 0.39 & B \\
\hline 66.14079 & 150.17242 & 2004 & 6.9 & 2.62 & 0.27 & B \\
\hline 66.10976 & 150.15785 & 2004 & 8.7 & 3.39 & 0.45 & B \\
\hline 66.10515 & 150.15355 & 2004 & 8.4 & 2.17 & 0.17 & B \\
\hline 66.07446 & 150.16788 & 2004 & 7.2 & 2.95 & 0.16 & B \\
\hline 66.07199 & 150.16674 & 2004 & 4.4 & 0.13 & 0.49 & B \\
\hline 65.34931 & 146.66884 & 2004 & 14.2 & 2.82 & 0.29 & B \\
\hline 65.35094 & 146.67092 & 2004 & 11.8 & 3.05 & 0.26 & B \\
\hline 65.35313 & 146.67368 & 2004 & 10.1 & 3.56 & 0.18 & B \\
\hline 65.1234 & 147.46541 & 2004 & 18 & 3.51 & 0.1 & B \\
\hline 65.15298 & 147.48117 & 2004 & 10.2 & 0.8 & 0.1 & B \\
\hline 65.15089 & 147.47616 & 2004 & 12.8 & 2.18 & 0.19 & B \\
\hline 65.14843 & 147.47171 & 2004 & 19.6 & 2.15 & 0.1 & B \\
\hline 65.15299 & 147.47819 & 2004 & 13.3 & 1.09 & 0.08 & B \\
\hline 65.1424 & 147.4649 & 2004 & 18.7 & 4.37 & 0.48 & B \\
\hline 65.14189 & 147.46556 & 2004 & 24.9 & 6.82 & 0.55 & B \\
\hline 65.31961 & 146.71884 & 2004 & 5 & 1.69 & 0 & B \\
\hline 64.3361 & 145.6895 & 2010 & 20.58 & 2.85 & 1.57 & $\mathrm{R}$ \\
\hline 64.3391 & 145.7729 & 2010 & 20.26 & 1.82 & 0.67 & $\mathrm{R}$ \\
\hline 64.3376 & 145.7697 & 2010 & 15.99 & 1.12 & 0.47 & $\mathrm{R}$ \\
\hline 64.3352 & 145.778 & 2010 & 25.51 & 2.22 & 0.49 & $\mathrm{R}$ \\
\hline 64.3379 & 145.6912 & 2010 & 18.15 & 2.13 & 0.77 & $\mathrm{R}$ \\
\hline 64.3363 & 145.7046 & 2010 & 16.55 & 1.68 & 0.59 & $\mathrm{R}$ \\
\hline 64.3357 & 145.7263 & 2010 & 22.14 & 2.51 & 0.84 & $\mathrm{R}$ \\
\hline 64.3345 & 145.7304 & 2010 & 20.53 & 2.1 & 1.25 & $\mathrm{R}$ \\
\hline
\end{tabular}




\begin{tabular}{|c|c|c|c|c|c|}
\hline 64.3358 & 145.7373 & 2010 & 25.42 & 3.18 & 0.93 \\
\hline 64.3299 & 145.7329 & 2010 & 24.03 & 2.75 & 0.74 \\
\hline 64.3344 & 145.7616 & 2010 & 11.78 & 1.59 & 0.4 \\
\hline 64.334 & 145.7632 & 2010 & 8.8 & 0.85 & 0.15 \\
\hline 64.3311 & 145.7511 & 2010 & 17.07 & 1.87 & 0.8 \\
\hline 64.3289 & 145.7531 & 2010 & 18.5 & 1.32 & 1.01 \\
\hline 64.3321 & 145.716 & 2010 & 17.1 & 1.9 & 0.96 \\
\hline 64.3321 & 145.7117 & 2010 & 10.64 & 1.42 & 0.81 \\
\hline 64.3353 & 145.7112 & 2010 & 9.78 & 2.17 & 1.09 \\
\hline 62.69135 & 141.5316 & 2003 & 14 & $\mathrm{~L}$ & I \\
\hline 65.60289 & 144.59124 & 2004 & 5.2 & S & I \\
\hline 65.52503 & 145.2483 & 2004 & 16 & EW & I \\
\hline 65.59183 & 144.66509 & 2004 & 21.7 & $\mathrm{~L}$ & I \\
\hline 65.12033 & 147.43199 & 2004 & 19.8 & $\mathrm{~N}$ & I \\
\hline 65.1164 & 147.42756 & 2004 & 24.3 & $\mathrm{~N}$ & I \\
\hline 65.11822 & 147.42861 & 2004 & 21.5 & $\mathrm{~N}$ & I \\
\hline 65.12245 & 147.43168 & 2004 & 28.3 & $\mathrm{~N}$ & I \\
\hline 65.12361 & 147.43289 & 2004 & 15 & EW & I \\
\hline 65.35294 & 146.19033 & 2004 & 24.9 & $\mathrm{~S}$ & I \\
\hline 65.33454 & 146.78486 & 2004 & 26.5 & EW & I \\
\hline 65.34025 & 146.72826 & 2004 & 25.7 & $\mathrm{~S}$ & I \\
\hline 65.34 & 146.72 & 2004 & 13.5 & S & I \\
\hline 65.33924 & 146.70056 & 2004 & 13.2 & $S$ & I \\
\hline 65.34652 & 146.66863 & 2004 & 12.6 & S & I \\
\hline 65.34354 & 146.68043 & 2004 & 16.1 & $S$ & I \\
\hline 65.11629 & 147.42466 & 2004 & 27.9 & $\mathrm{~N}$ & I \\
\hline 65.11974 & 147.4258 & 2004 & 26.5 & $\mathrm{~N}$ & I \\
\hline 65.22076 & 147.13165 & 2004 & 7.9 & $\mathrm{~S}$ & I \\
\hline 65.23367 & 147.13132 & 2004 & 28.3 & EW & I \\
\hline 65.14158 & 147.40933 & 2004 & 8.9 & $\mathrm{~S}$ & I \\
\hline 65.14318 & 147.41279 & 2004 & 12.6 & $\mathrm{~S}$ & I \\
\hline 65.35098 & 146.67121 & 2004 & 20.2 & EW & I \\
\hline 65.33582 & 146.75432 & 2004 & 13.8 & $\mathrm{~S}$ & I \\
\hline 65.33695 & 146.78448 & 2004 & 11.4 & EW & I \\
\hline 65.3303 & 146.71143 & 2004 & 18 & $\mathrm{~L}$ & I \\
\hline 65.34133 & 146.73332 & 2004 & 19.9 & $\mathrm{U}$ & I \\
\hline 65.1532 & 147.47236 & 2004 & 19.6 & $\mathrm{~L}$ & I \\
\hline 65.15395 & 147.47608 & 2004 & 21.7 & $\mathrm{~S}$ & I \\
\hline 67.0571 & 150.35113 & 2005 & 20.4 & EW & I \\
\hline 66.16383 & 150.20323 & 2004 & 21.7 & $\mathrm{~S}$ & I \\
\hline 66.16169 & 150.19053 & 2004 & 17.1 & S & I \\
\hline 66.14033 & 150.17171 & 2004 & 12.5 & $\mathrm{~L}$ & I \\
\hline 66.15354 & 150.1829 & 2004 & 15.5 & $\mathrm{~L}$ & I \\
\hline
\end{tabular}




\begin{tabular}{|c|c|c|c|c|c|}
\hline 66.31301 & 150.39406 & 2004 & 16.5 & EW & I \\
\hline 66.10431 & 150.15702 & 2004 & 12.6 & $\mathrm{~N}$ & I \\
\hline 66.185 & 150.9016 & 2004 & 15.3 & $\mathrm{~S}$ & I \\
\hline 66.1827 & 150.21915 & 2004 & 19.3 & EW & I \\
\hline 66.21236 & 150.25108 & 2004 & 19.5 & EW & I \\
\hline 66.20321 & 150.2298 & 2004 & 24.7 & EW & I \\
\hline 66.19379 & 150.21366 & 2004 & 15.7 & EW & I \\
\hline 65.65362 & 149.07944 & 2003 & 6.3 & $\mathrm{~N}$ & I \\
\hline 65.64965 & 149.0926 & 2003 & 12.4 & $\mathrm{~N}$ & I \\
\hline 65.57709 & 148.94883 & 2003 & 6.5 & EW & I \\
\hline 65.57687 & 148.96002 & 2003 & 6.9 & EW & I \\
\hline 65.62037 & 149.09044 & 2003 & 8.6 & $\mathrm{~N}$ & I \\
\hline 65.62163 & 149.0894 & 2003 & 15.9 & $\mathrm{~N}$ & I \\
\hline 65.62382 & 149.0877 & 2003 & 15.7 & $\mathrm{~N}$ & I \\
\hline 65.6232 & 149.08344 & 2003 & 17 & EW & I \\
\hline 65.61944 & 149.08718 & 2003 & 14 & $\mathrm{~N}$ & I \\
\hline 65.61905 & 149.08413 & 2003 & 14.8 & EW & I \\
\hline 65.61845 & 149.08334 & 2003 & 10.5 & EW & I \\
\hline 65.61856 & 149.08218 & 2003 & 12 & EW & I \\
\hline 65.61984 & 149.08445 & 2003 & 14.8 & EW & I \\
\hline 65.57657 & 148.94145 & 2003 & 14.3 & EW & I \\
\hline 65.57617 & 148.94231 & 2003 & 17.5 & EW & I \\
\hline 65.62004 & 149.08567 & 2003 & 16.8 & $\mathrm{~N}$ & I \\
\hline 65.61827 & 149.08567 & 2003 & 14.8 & $\mathrm{~N}$ & I \\
\hline 62.83133 & 141.3446 & 2004 & 8.4 & $\mathrm{~L}$ & I \\
\hline 64.39635 & 141.40998 & 2004 & 7.3 & $\mathrm{~S}$ & I \\
\hline 64.39487 & 141.40833 & 2004 & 9.9 & $\mathrm{~S}$ & I \\
\hline 65.30351 & 149.08207 & 2002 & 10.9 & EW & I \\
\hline 65.27854 & 149.02062 & 2002 & 18.1 & EW & I \\
\hline 66.79057 & 150.6909 & 2005 & 12.7 & $\mathrm{~L}$ & I \\
\hline 66.65007 & 150.66595 & 2005 & 21.7 & $S$ & I \\
\hline 63.24074 & 142.98912 & 2003 & 5.4 & $\mathrm{~L}$ & I \\
\hline 64.88385 & 146.30439 & 2004 & 31.4 & $\mathrm{~N}$ & I \\
\hline 64.88652 & 146.30662 & 2004 & 23.7 & $\mathrm{~L}$ & I \\
\hline 64.90098 & 146.34856 & 2004 & 13.2 & EW & I \\
\hline 64.90023 & 146.35068 & 2004 & 12.4 & EW & I \\
\hline 64.89008 & 146.31987 & 2004 & 22.3 & EW & I \\
\hline 64.88198 & 146.30219 & 2004 & 31 & EW & I \\
\hline 64.88446 & 146.30585 & 2004 & 34.2 & $\mathrm{~N}$ & I \\
\hline 64.88764 & 146.31305 & 2004 & 33 & EW & I \\
\hline 64.88784 & 146.30975 & 2004 & 30.4 & $\mathrm{~L}$ & I \\
\hline 64.88728 & 146.31067 & 2004 & 32.2 & $\mathrm{~L}$ & I \\
\hline 64.88513 & 146.30717 & 2004 & 30.6 & $\mathrm{~L}$ & l \\
\hline
\end{tabular}




$\begin{array}{ccccccc}64.88329 & 146.30423 & 2004 & 33.4 & \mathrm{~N} & / & \mathrm{T} \\ 64.90092 & 146.35126 & 2004 & 5.3 & \mathrm{EW} & / & \mathrm{T} \\ 64.90054 & 146.34386 & 2004 & 8.6 & \mathrm{~L} & / & \mathrm{T} \\ 64.9003 & 146.33406 & 2004 & 9.9 & \mathrm{EW} & / & \mathrm{T} \\ 64.8918 & 146.31235 & 2004 & 14.6 & \mathrm{EW} & / & \mathrm{T} \\ 64.88745 & 146.30784 & 2004 & 25.6 & \mathrm{~L} & / & \mathrm{T} \\ 64.88578 & 146.30284 & 2004 & 19 & \mathrm{~L} & / & \mathrm{T} \\ 64.88449 & 146.30113 & 2004 & 19.2 & \mathrm{EW} & / & \mathrm{T} \\ 64.88518 & 146.30065 & 2004 & 21.3 & \mathrm{EW} & / & \mathrm{T} \\ 64.08456 & 141.6474 & 2004 & 6.5 & \mathrm{~S} & \mathrm{~T}\end{array}$


Supplementary Table 3. Statistics (intercept, slope and correlation) of the linear relationship between annual burned area, carbon emissions and carbon consumption from the Alaskan fire Emissions Database (AKFED) and the Global Fire Emissions Database version 3s (GFED3s) between 2001 and 2010 at 0.25 ${ }^{\circ}$ resolution between $58^{\circ}$ and $71.5^{\circ} \mathrm{N}$, and $141^{\circ}$ and $168^{\circ} \mathrm{W}$. The strength of the correlation was assessed using the Pearson coefficient and type 2 regression was applied for the line fitting with the AKFED estimates as independent variable and GFED3s variables as dependent variable.

\begin{tabular}{|c|c|c|c|c|c|c|c|c|c|c|c|c|c|}
\hline \multirow[b]{2}{*}{ year } & \multicolumn{5}{|c|}{ annual burned area (kha) } & \multicolumn{5}{|c|}{ carbon emissions $(\mathrm{Tg})$} & \multicolumn{3}{|c|}{ carbon consumption $(\mathrm{kg} / \mathrm{m} 2)$} \\
\hline & AKFED & GFED3s & intercept & slope & $\mathrm{r}$ & AKFED & GFED3s & intercept & slope & $\mathrm{r}$ & AKFED & GFED3s & $\mathrm{r}$ \\
\hline 2001 & 57 & 2 & 0.04 & 0.01 & $0.42 *$ & 1 & 0 & 0.00 & 0.01 & 0.27 & 2.50 & 1.58 & -0.60 \\
\hline 2002 & 723 & 636 & -0.02 & 0.89 & $0.98 *$ & 16 & 15 & 0.00 & 0.93 & $0.94 *$ & 2.27 & 2.59 & -0.06 \\
\hline 2003 & 194 & 200 & 0.05 & 1.01 & $0.93 *$ & 5 & 5 & 0.00 & 0.93 & $0.89 *$ & 2.54 & 2.83 & -0.18 \\
\hline 2004 & 2268 & 2283 & -0.05 & 1.02 & $0.95 *$ & 67 & 52 & 0.00 & 0.65 & $0.85 *$ & 2.83 & 2.55 & -0.02 \\
\hline 2005 & 1640 & 1538 & 0.15 & 0.89 & $0.95 *$ & 44 & 38 & 0.00 & 0.73 & $0.86^{*}$ & 2.55 & 2.68 & 0.02 \\
\hline 2006 & 46 & 86 & 0.28 & 1.31 & $0.88^{*}$ & 1 & 2 & 0.00 & 2.20 & $0.92 *$ & 1.77 & 2.59 & -0.31 \\
\hline 2007 & 196 & 165 & 0.23 & 0.59 & $0.84^{*}$ & 5 & 5 & 0.00 & 0.68 & $0.82 *$ & 2.28 & 2.83 & 0.08 \\
\hline 2008 & 35 & 34 & 0.03 & 0.89 & $0.97 *$ & 1 & 1 & 0.00 & 0.61 & $0.94 *$ & 2.15 & 2.12 & 0.02 \\
\hline 2009 & 1030 & 1130 & 0.05 & 1.08 & $0.98 *$ & 25 & 29 & 0.00 & 1.16 & $0.94 *$ & 2.42 & 2.46 & $-0.32 *$ \\
\hline 2010 & 260 & 324 & 0.19 & 1.05 & $0.88^{*}$ & 6 & 8 & 0.00 & 1.18 & $0.81 *$ & 2.16 & 2.32 & -0.01 \\
\hline $\begin{array}{l}2001-2010 \\
p<0.05\end{array}$ & 6449 & 6399 & 0.04 & 0.98 & $0.95 *$ & 171 & 154 & 0.00 & 0.79 & $0.87 *$ & 2.48 & 2.57 & -0.04 \\
\hline
\end{tabular}



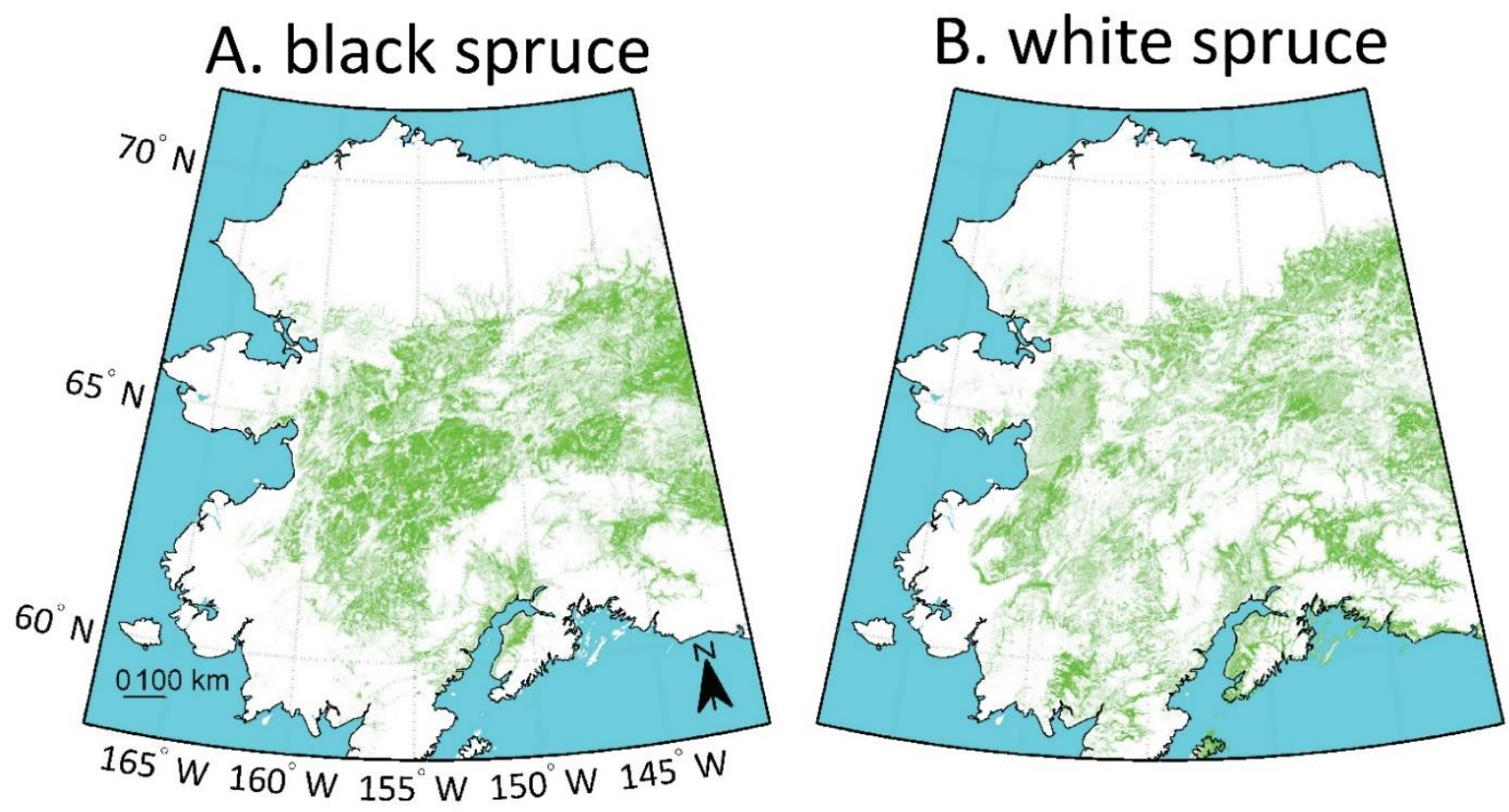

\section{C. deciduous}
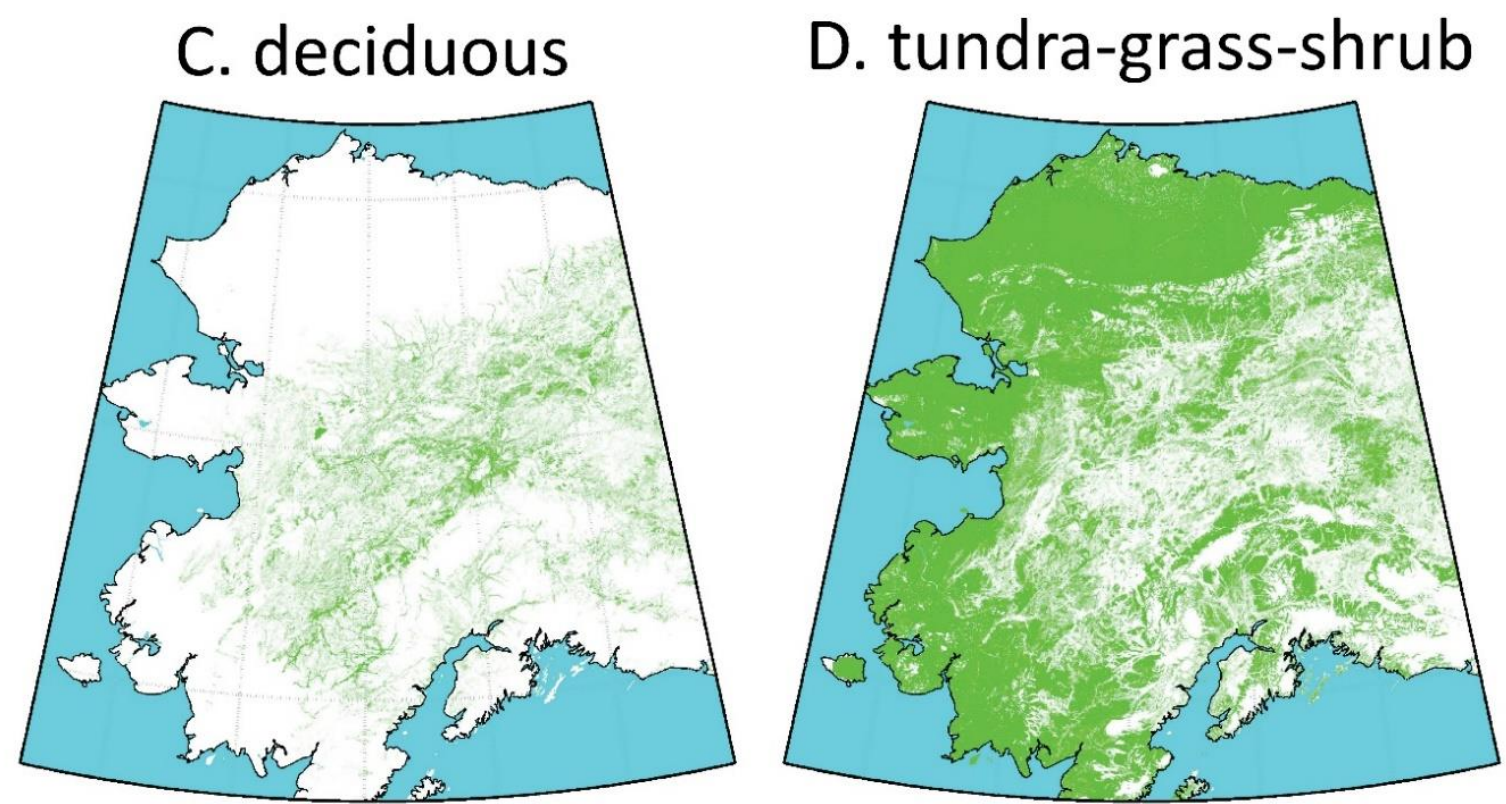

\section{fractional cover}

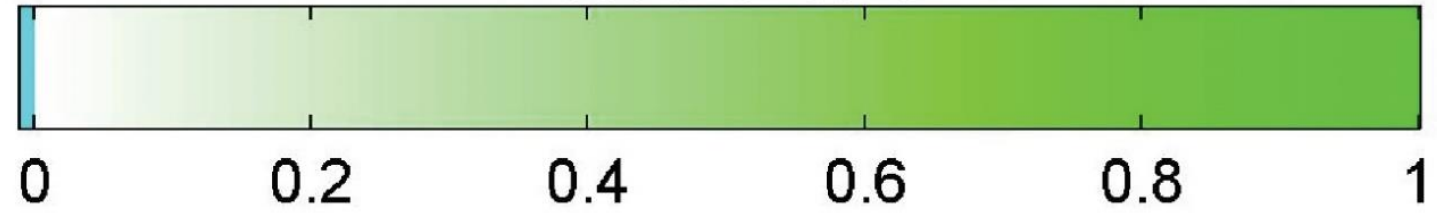

Supplementary Figure 1. Fractional cover maps of (A) black spruce, (B) white spruce, (C) deciduous trees and (D) tundra-grassland-shrubland. The maps represent the per-pixel fractional cover at $500 \mathrm{~m}$ of the aggregated land cover classes (Table S1) of the $30 \mathrm{~m}$ Fuel Characteristic Classification System (Ottmar et al., 2007) map for the year 2000. 


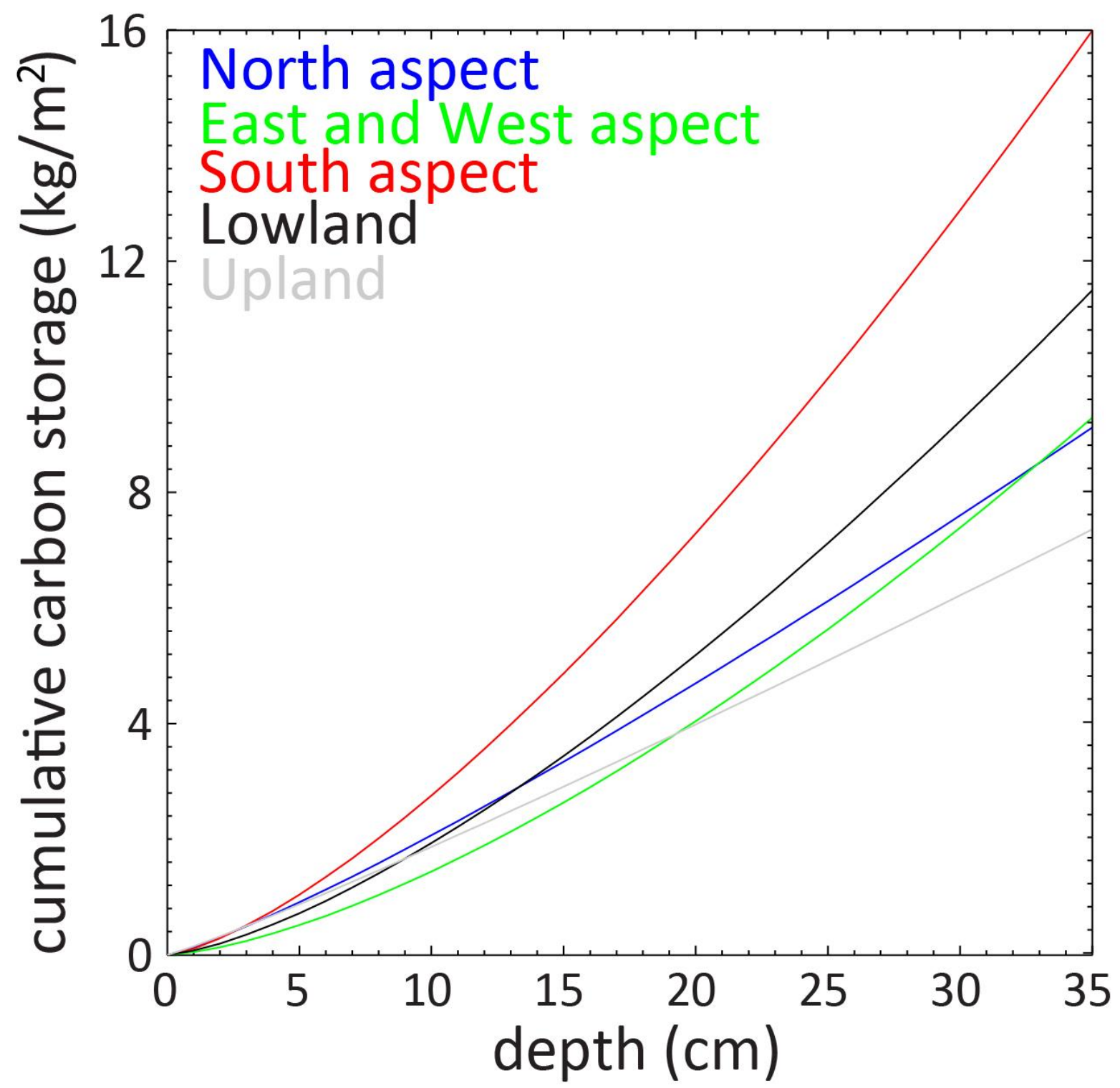

Supplementary Figure 2. Relationships between cumulative belowground carbon storage and depth for different topographic classes after Turetsky et al. (2011). 


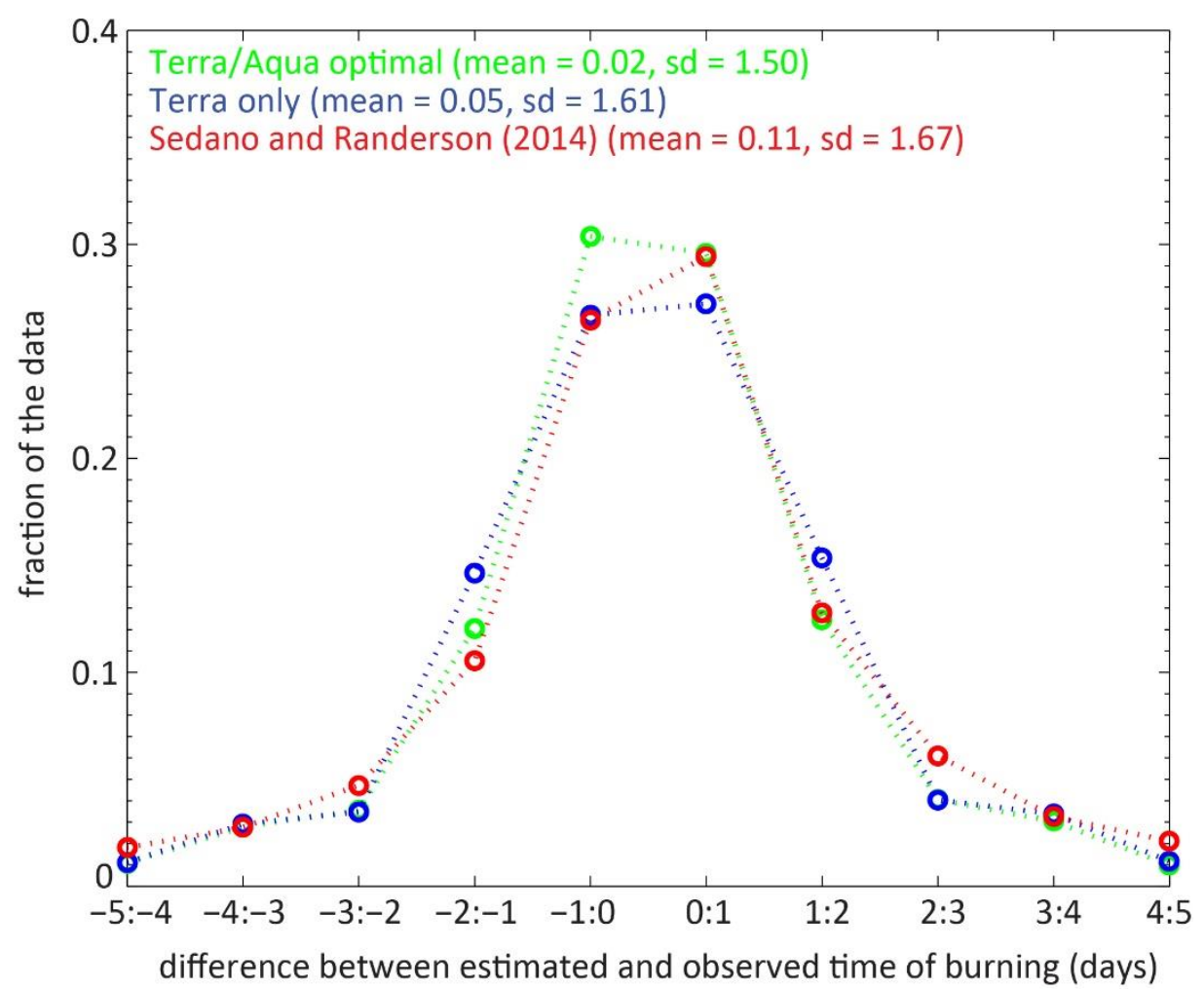

Supplementary Figure 3. Distribution of the difference between estimated and observed time of burning derived from the inverse distance weighting interpolation technique. The optimal setting for each pixel was defined by the value of the closest active fire detection with exclusion of active fire detections with scan angles higher than $40^{\circ}$. Sedano and Randerson (2014) did not exclude observations based on scan angle, considered a maximum of the ten closest pixels within a circular neighborhood with a $1 \mathrm{~km}$ radius, and used a weighting power of two for the interpolation. We used the large fire year of 2004 as subset for interpolation optimization. We varied three parameters in the optimzation: (1) the number of active fire detections considered to derive the time of burning for each pixel, (2) the weighting factor and (3) the threshold for exclusion of active fire detections with high scan angles. We varied the number of active fire detections included in the interpolation in steps of one between one and five, the power of the weigthing factor in steps of one between one and five and the exclusion threshold of scan angles in steps of $5^{\circ}$ between $5^{\circ}$ and $50^{\circ}$. For each combination of included active fire detections, weigthing power and scan angle exclusion threshold, we randomly selected $90 \%$ of the active fire detections for the progression interpolation. The remaining $10 \%$ was then used to validate the derived time of burning. We repeated this process ten times per combination in a fashion that every single active fire pixel had been nine times part of the interpolation dataset and one time of the validation dataset. We then used the mean and standard deviation of the distribution of the difference between the time of burning of the interpolation and validation dataset for each combination as quality indicator for the optimization. For the year 2001 of our study only Terra data is available, and we therefore repeated the optimal setting in a Terra-only scenario. (sd: standard deviation) 

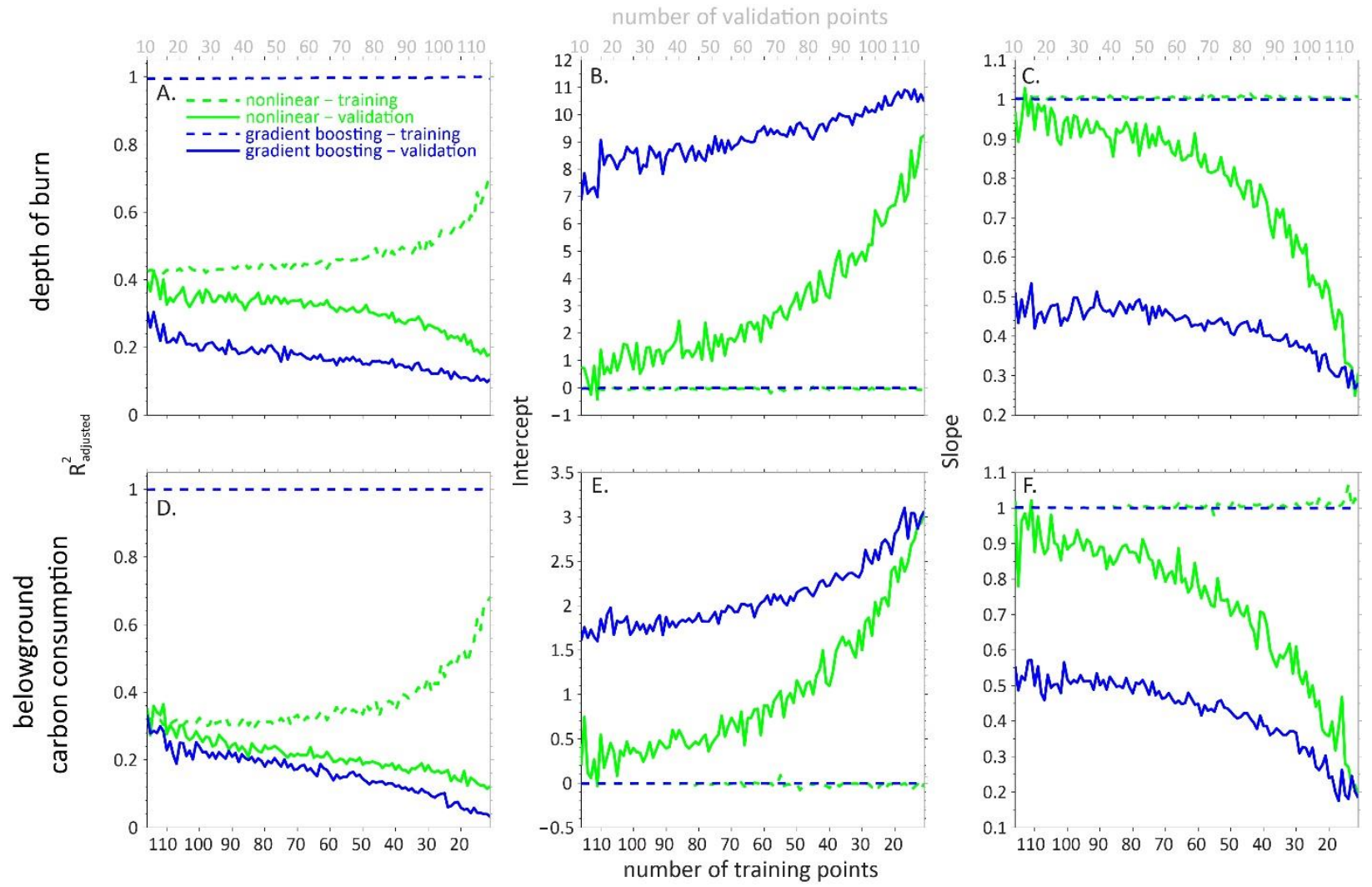

Supplementary Figure 4. $R_{\text {adjusted }}^{2}$, intercept and slope for the linear regression between observed and estimated values for training and validation plots in function of the number of training points for the depth of burn $(\mathrm{A}, \mathrm{B}$, and C) and belowground consumption model (D, E and F). To assess the robustness of the multiplicative nonlinear regression and gradient boosting techniques in our application to predict carbon consumption by fire in black spruce forests, we varied the number of field plots used as training data between 116 and 10, out of the total of 126 plots, in decreasing steps of one. The remainder of the plots was used for validation. For each combination of the number of training and validation plots, we randomly varied the selection of training and validation plots 100 times. For each combination and selection of training and validation plots, the prediction models were derived and applied on the validation data. The robustness for extrapolation of the models was then assessed as a function of the number of training plots by means of the $R_{\text {adjusted }}^{2}$, slope and intercept of the regression between estimated and observed values of the validation plots, averaged over the 100 random selections. While the gradient boosting technique revealed an apparent high performance $\left(R_{\text {adjusted }}^{2} \sim 1\right)$ for the training plots alone, its performance for the validation plots was consistently lower compared to the nonlinear regression models. In addition, the intercept and slope values of the linear regression between observed and estimated values for the validation plots deviated substantially from the expect values of zero and one for the gradient boosting technique, while these regression lines followed more closely the 1:1 line for the nonlinear models when at least approximately 70 field points were used for training. 

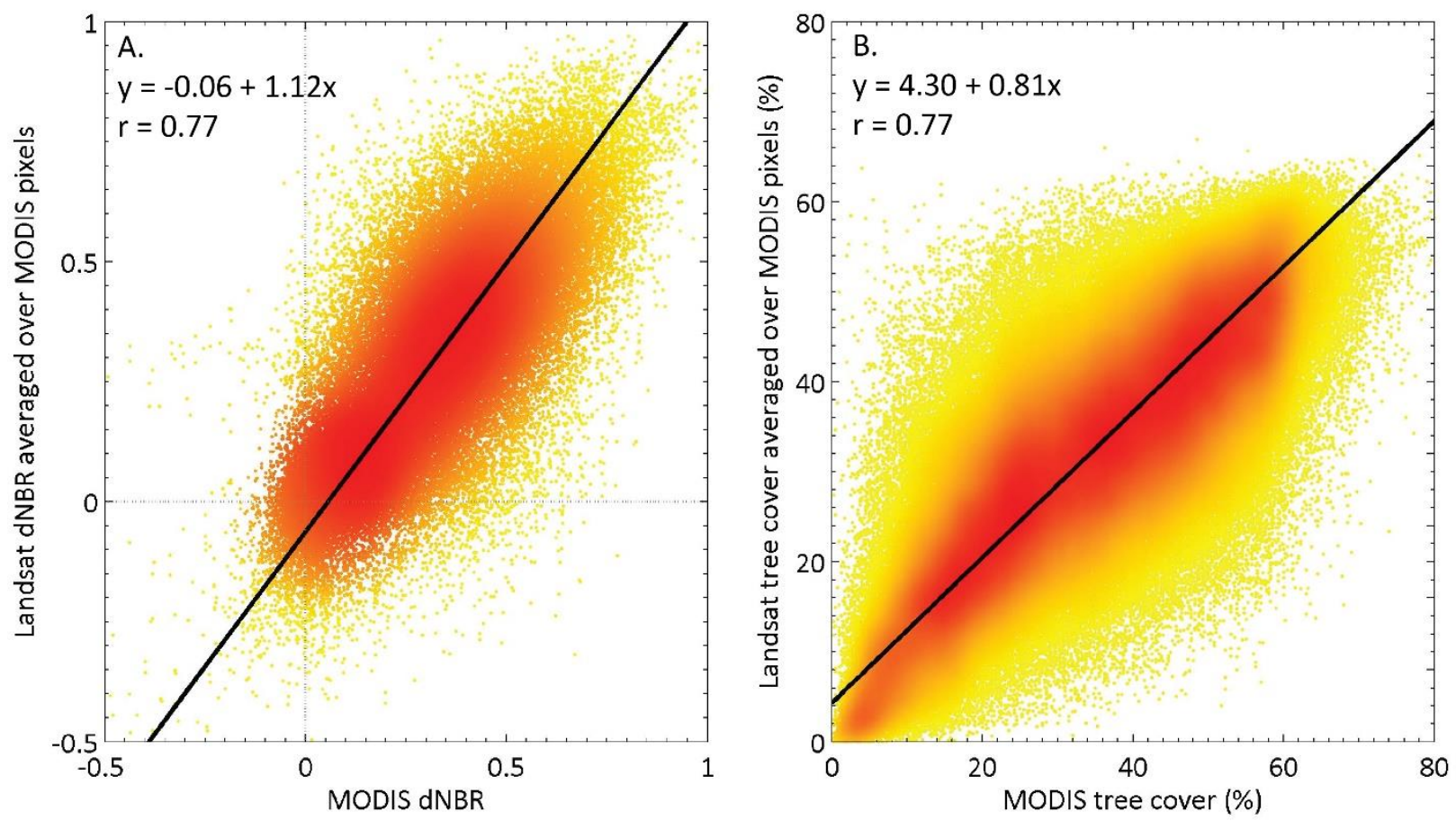

Supplementary Figure 5. Inter-sensor calibration between Landsat and the Moderate Resolution Imaging Spectroradiometer (MODIS) for (A) the differenced normalized burn ratio (dNBR) and (B) tree cover. For the dNBR comparison, all good-quality one-year post-fire observations of the large fire year 2004 from the Monitoring Trends in Burn Severity database (Eidenshink et al., 2007) were spatially averaged over MODIS pixels and compared with the corresponding dNBR values derived from the MOD13A1 product of 2004. For the tree cover comparison, all good-quality observations from the Landsat tree cover layer of the year 2000 (Sexton et al., 2013) that fell within the fire perimeters of the Alaskan Large Fire Database of the years 2001-2012 were spatially averaged over MODIS pixels and compared with the corresponding tree cover values of the MOD44B product of 2000. Type 2 regression was used to assess the linear relationship. 


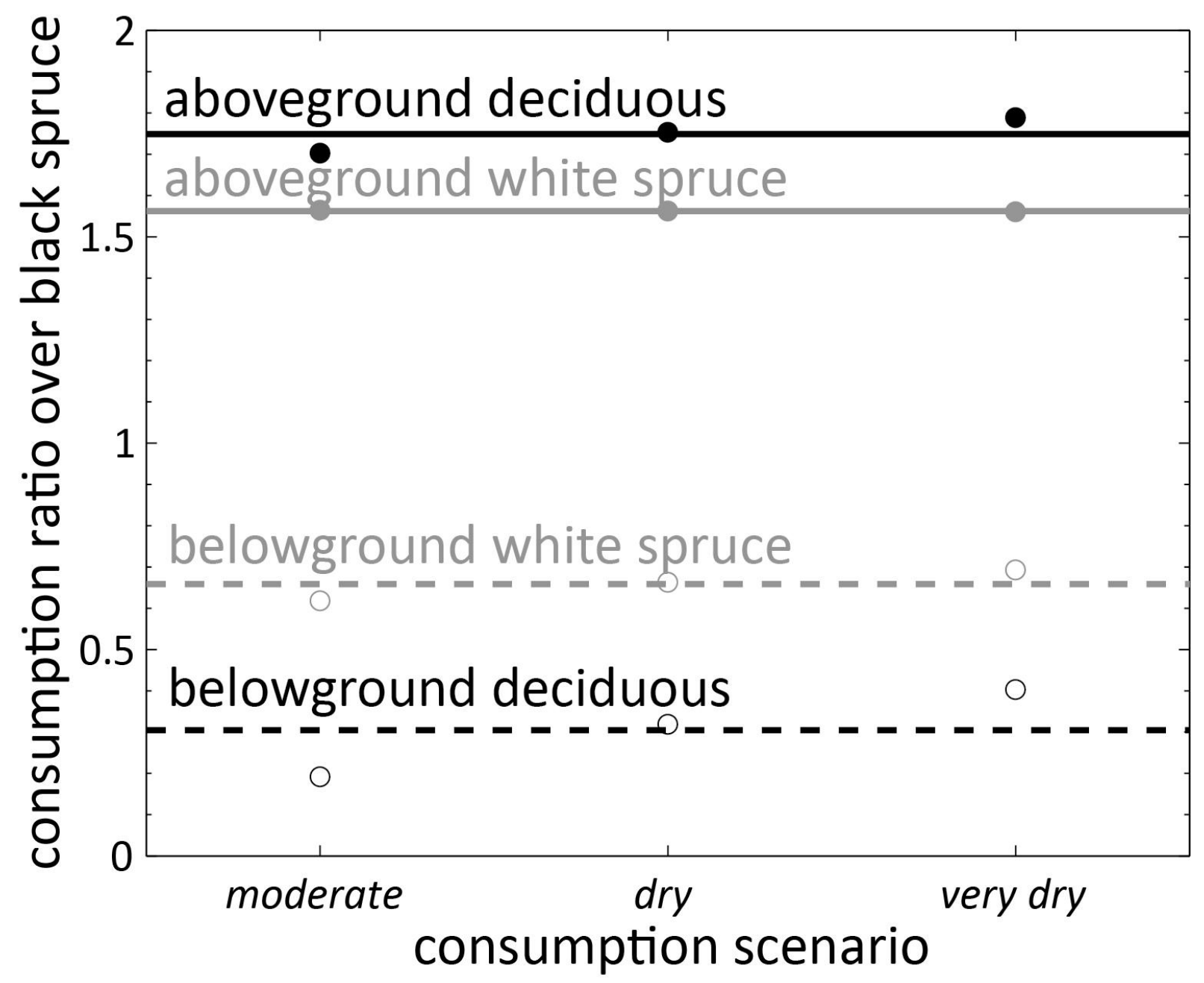

Supplementary Figure 6. Consumption ratios for above- and belowground white spruce/black spruce and deciduous/black spruce. Fuel consumption was estimated using Consume 3.0 (Ottmar et al., 2006) for black spruce (Fuel Characteristic Classification code 87), deciduous (93) and white spruce (101). Three consumption scenarios were applied: moderate (1000 h fuel moisture: $25 \%$; duff fuel moisture: $60 \%, 10 \mathrm{~h}$ fuel moisture: $13 \%)$; dry (1000 $\mathrm{h}$ fuel moisture: $15 \%$; duff fuel moisture: $40 \%, 10 \mathrm{~h}$ fuel moisture: $10 \%)$, dry (1000 h fuel moisture: 10\%; duff fuel moisture: 20\%, $10 \mathrm{~h}$ fuel moisture: $6 \%$ ). Consumption ratios were relatively constant among the three different consumption scenarios and we therefore calculated and used the mean consumption ratio from these three scenarios. 


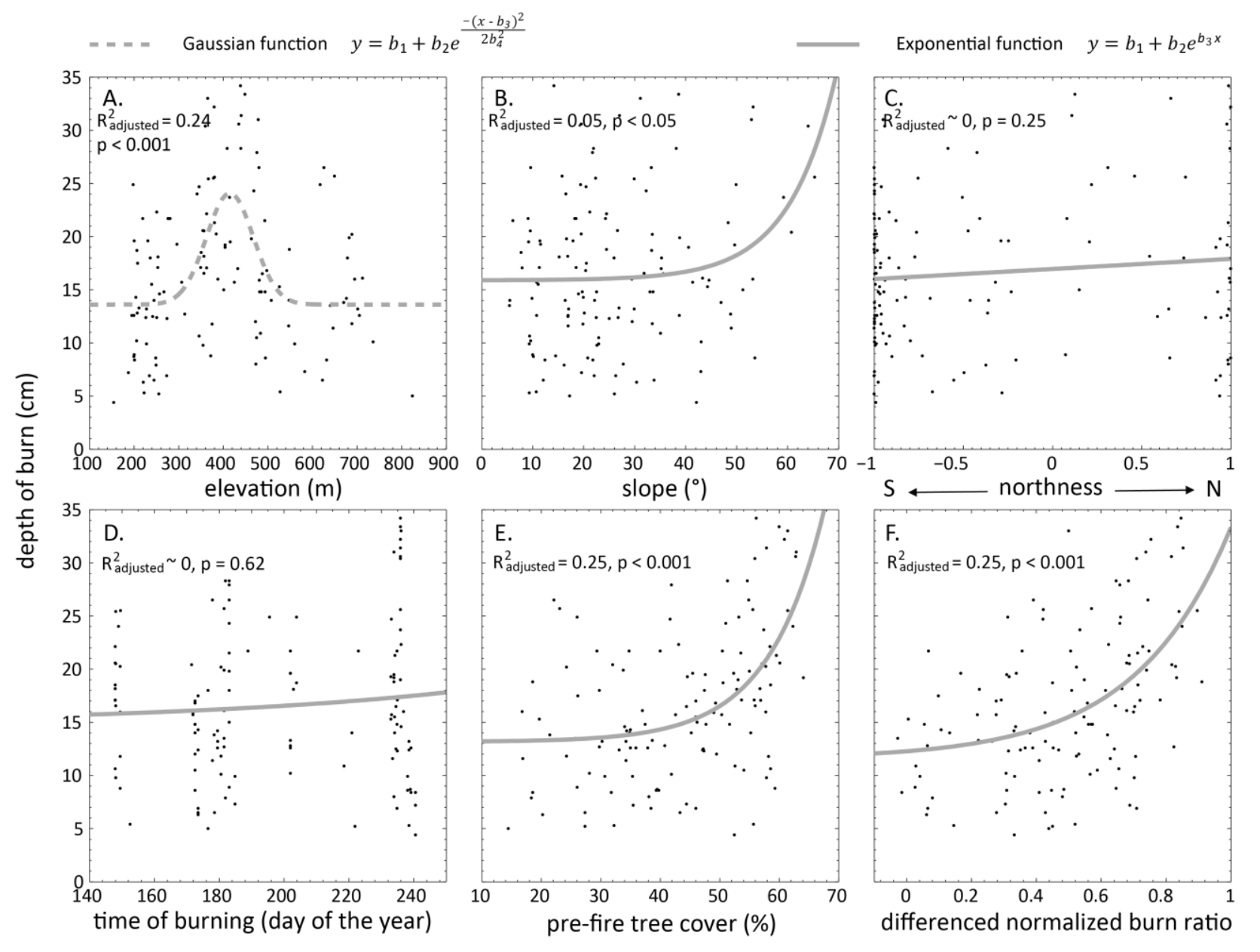

Supplementary Figure 7. Empirical relationships between the depth of burn from the field data and the environmental variables $(n=126)$. Depth of burn demonstrated a Gaussian response to elevation. The response function with the other variables was modeled as exponential. 


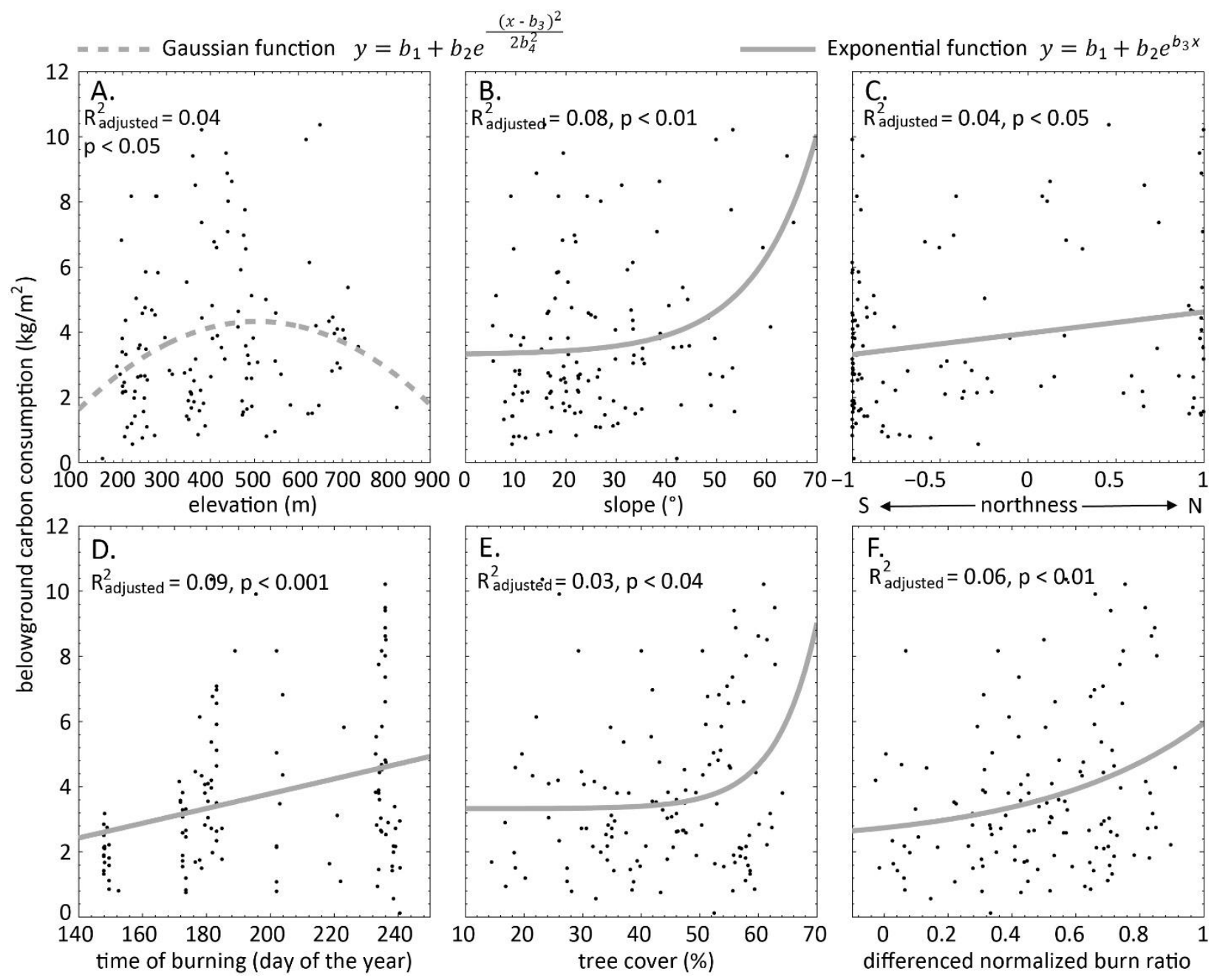

Supplementary Figure 8. Empirical relationships between the belowground carbon consumption from the field data and the environmental variables $(n=126)$. Belowground consumption demonstrated a Gaussian response to elevation. The response function with the other variables was modeled as exponential. 


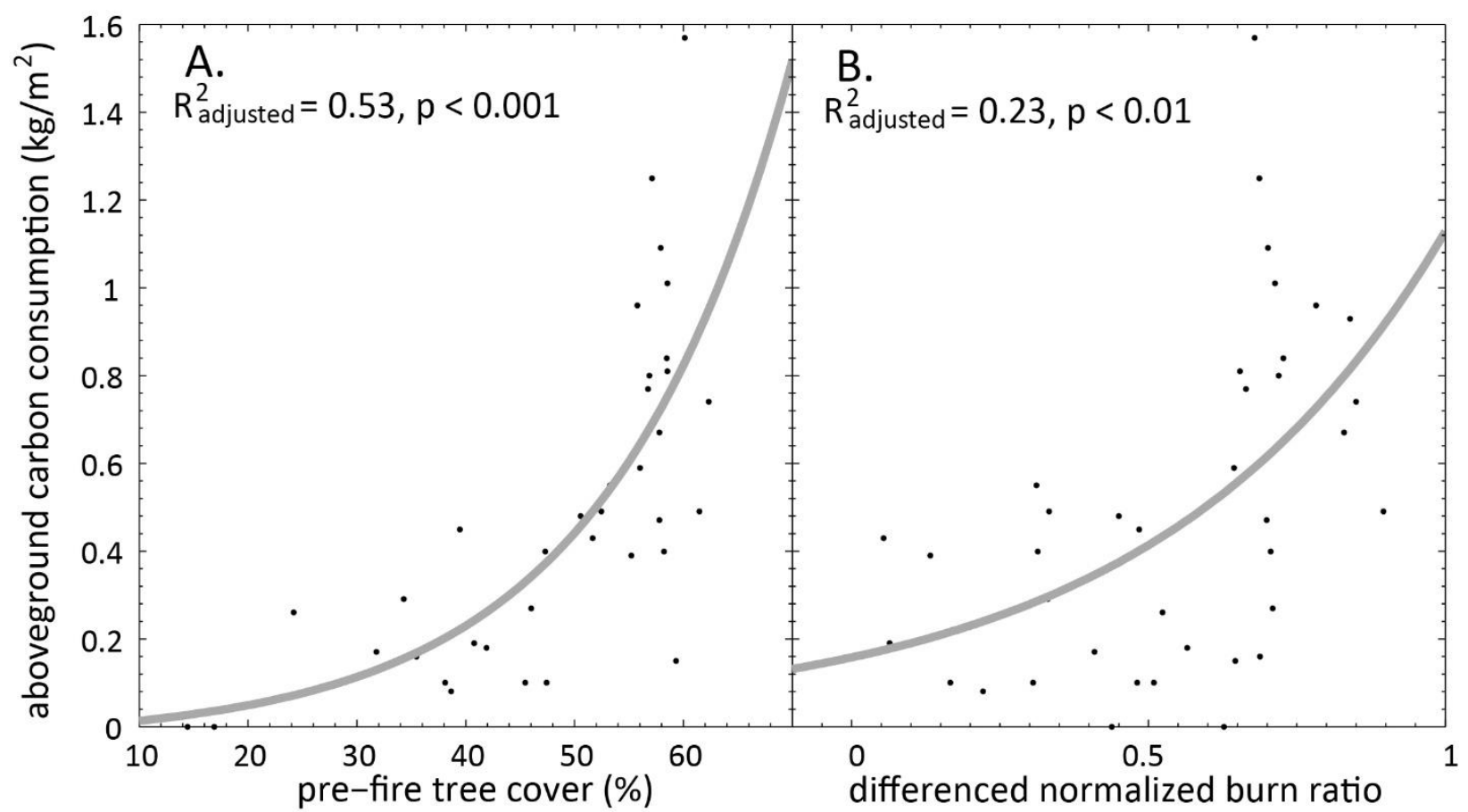

Supplementary Figure 9. Empirical exponential relationships between the aboveground carbon consumption from the field data and (A) the pre-fire tree cover and (B).the differenced normalized burn ratio $(n=38)$. 

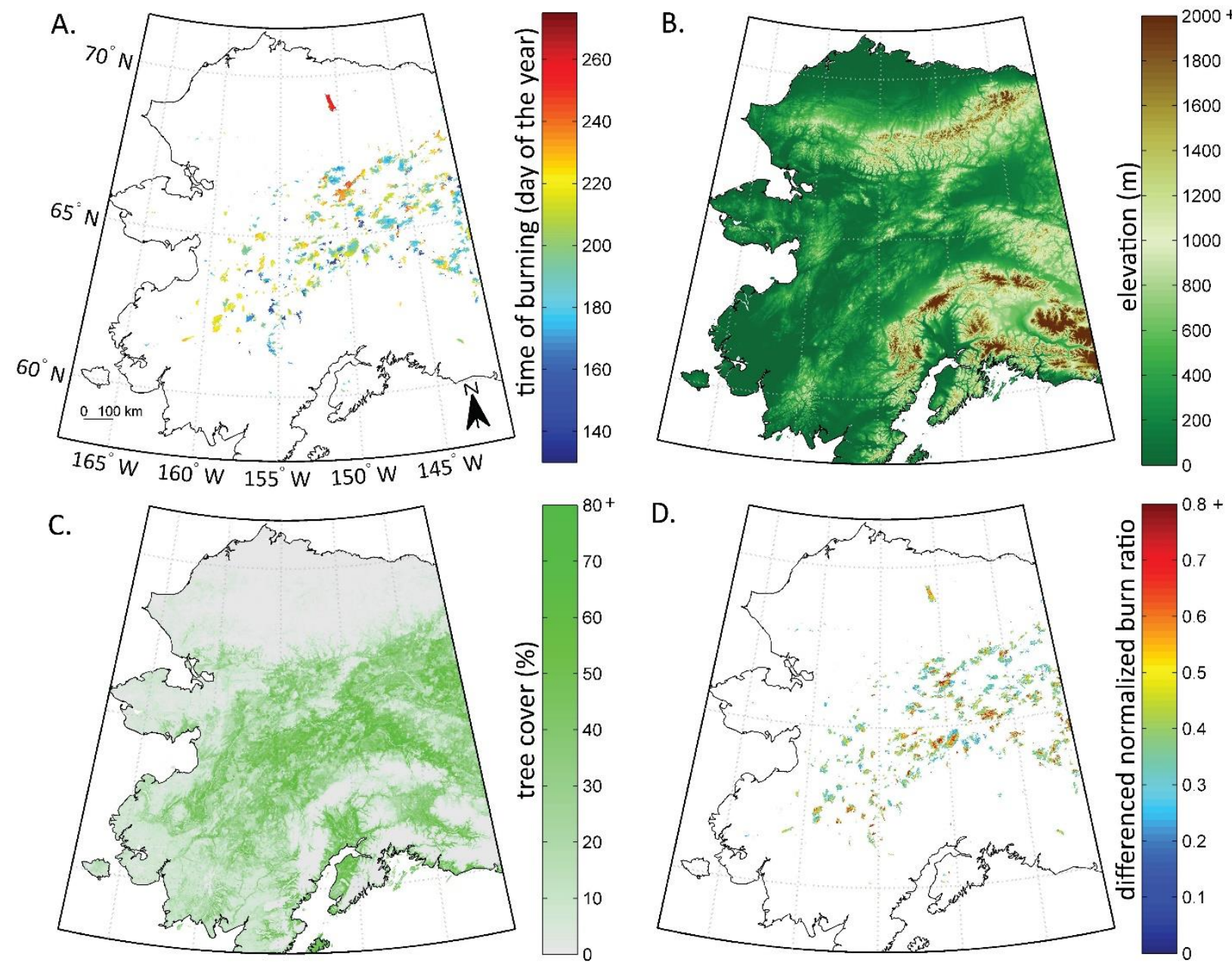

Supplementary Figure 10. Maps of (A) time of burning, (B) elevation, (C) tree cover and (D) differenced normalized burn ratio (dNBR) for the spatiotemporal domain of the study. The tree cover map of the year 2000 is shown. In the rare case a pixel burned more than once $(<1 \%$ of the burned pixels), the average of the multiple burn observations was plotted for time of burning and dNBR. 

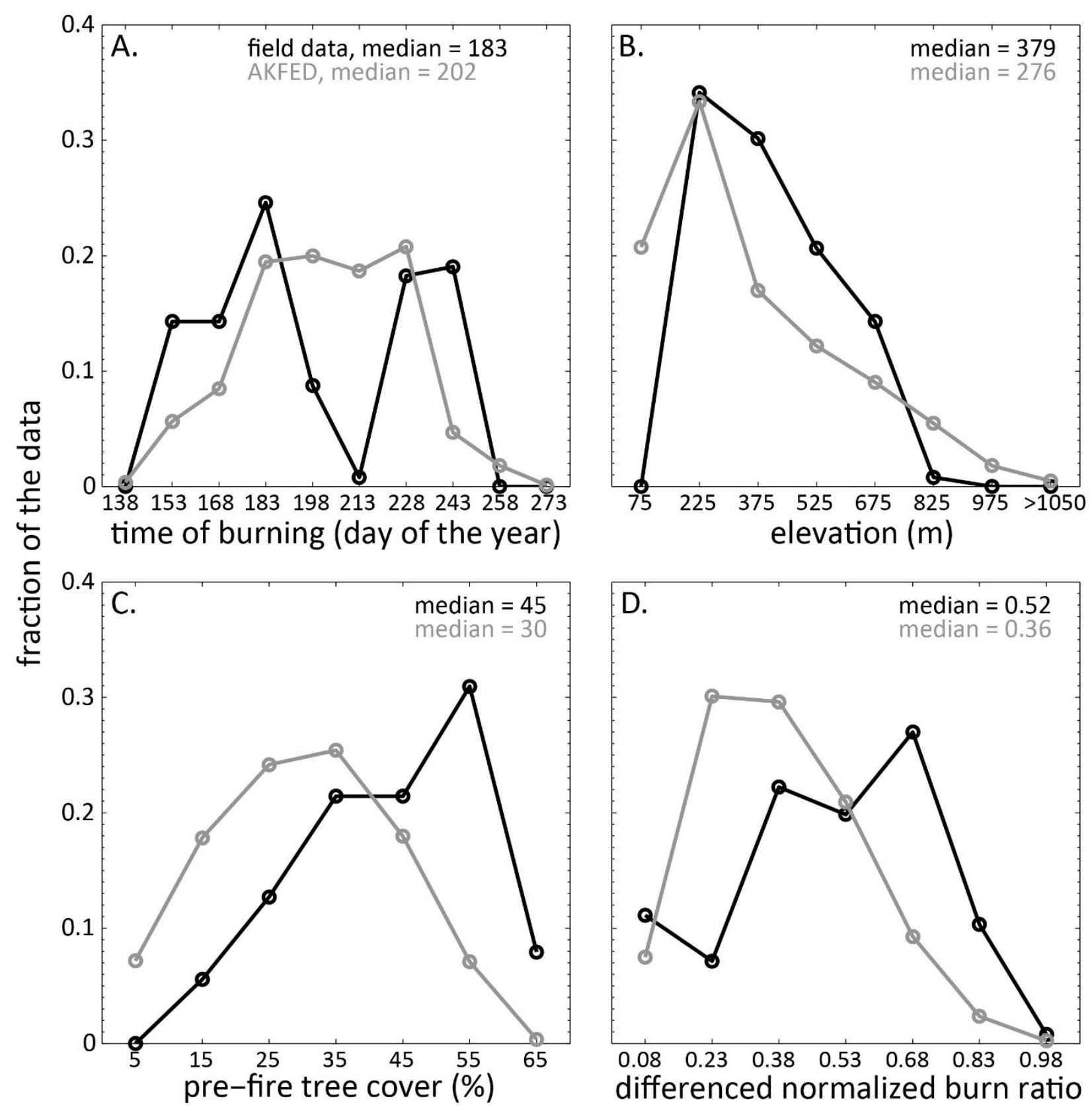

Supplementary Figure 11. Distribution of (A) time of burning, (B) elevation, (C) pre-fire tree cover, (D) differenced normalized burn ratio of field data and the Alaskan Fire Emissions Database (AKFED) between 2001 and 2012. The tree cover and differenced normalized burn ratio derived from the Moderate Resolution Imaging Spectroradiometer were converted to their Landsat-like values using the equations in Figure S5. The x-axes are labeled with the center of the binning intervals. 


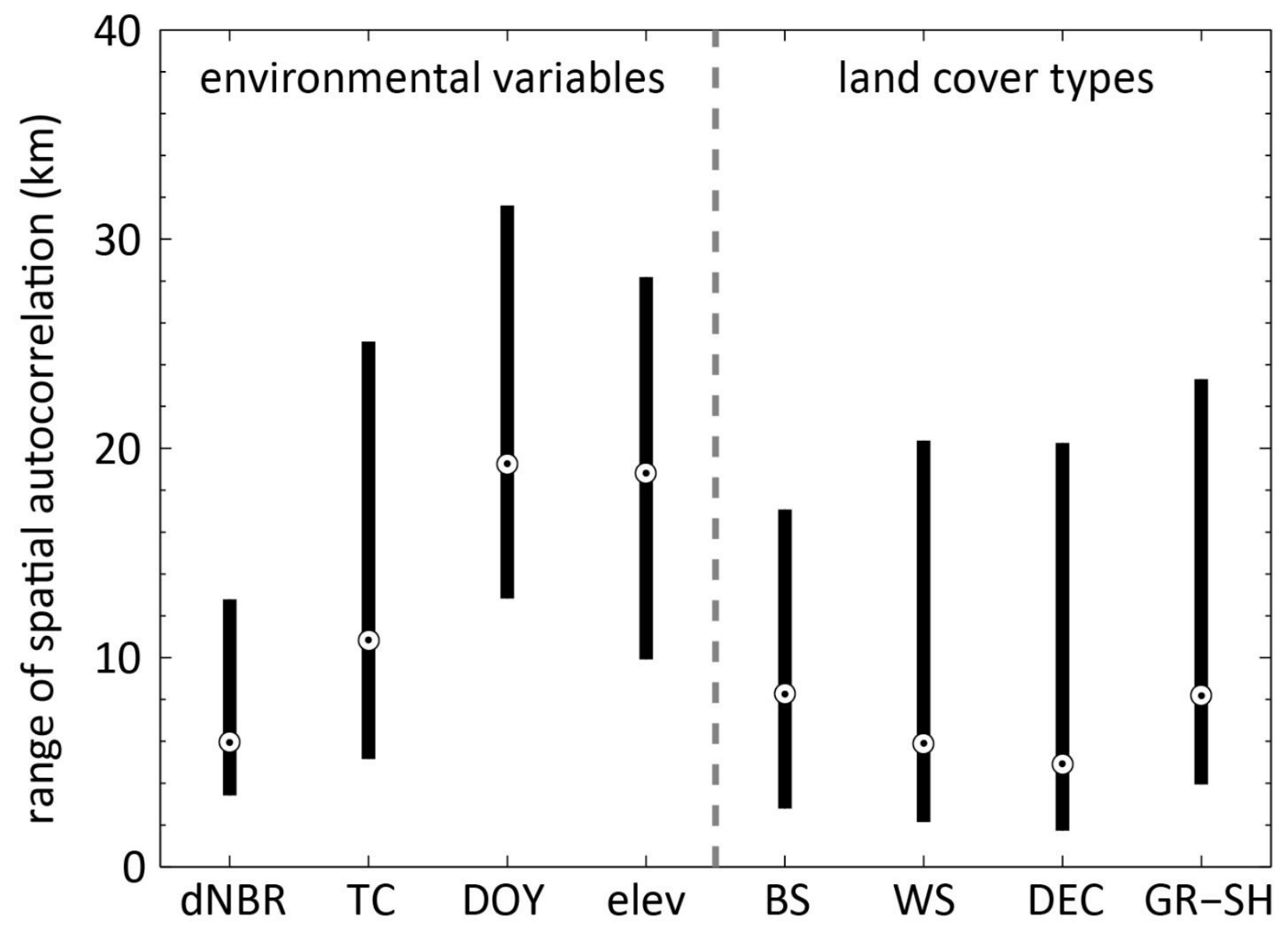

Supplementary Figure 12. Range of spatial autocorrelation of environmental variables and land cover types within all perimeters with a burned area larger than 10000 ha. A spherical variogram fit was performed for all environmental variables and land cover types within these perimeters. The range of the variogram fit quantifies the degree to which variables are spatially correlated. At distances smaller than the range observations are spatially correlated, at distances larger than the range they are not. (dNBR: differenced normalized burn ratio, TC: tree cover, DOY: day of the year, elev: elevation, BS: black spruce, WS: white spruce, DEC: deciduous, GR-SH: grass-shrub). 